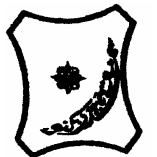

Bayero Journal of Pure and Applied Sciences, 6(1): 1 - 6

Received: September 2012

Accepted: May 2013

ISSN $2006-6996$

\title{
ANTI-PLASMODIAL ACTIVITIES OF SOME PLANTS EXTRACTS USED IN TRADITIONAL MALARIA THERAPY IN KANO-NIGERIA
}

\author{
*Dabo ${ }^{1}$, N.T., ${ }^{3}$ Ofori $^{2}$, M., Nyarko ${ }^{2}$, A. K., Edo ${ }^{3}$, D. and Bimi, L. ${ }^{3}$ \\ ${ }^{1}$ Department of Biological Sciences, Bayero University, Kano, Nigeria. \\ ${ }^{2}$ Noguchi Memorial Institute of Medical Research, (NMIMR), University of Ghana, Legon, Ghana \\ ${ }^{3}$ Department of Animal Biology and Conservation Science (DABCS), University of Ghana, Legon, Ghana \\ *Correspondence author: ntdabo@gmail.com
}

\begin{abstract}
This work was set to evaluate the antiplasmodial activities of some plants used in traditional malaria therapy in Kano State, Nigeria. Nine medicinal plants, distributed into eight families, used for treatment of malaria fever by the Hausa people of Kano-Nigeria were selected based on the traditional claims of the folks. These were collected and extracted using aqueous and organic solvents. A total of nineteen extracts and forty four extract-fractions were obtained. Thirty extracts ( 7 aqueous extracts, 12 ethanol extracts and 11 methanol extracts-fraction) were selected and screened for their in vitro anti-plasmodial activities against laboratory adapted chloroquine susceptible Plasmodium falciparum strain 3D7. Seven (23.33\%) of these extracts that exhibited $70 \%$ or more inhibition at $50 \mu \mathrm{g} / \mathrm{mL}$ concentration were further evaluated to establish their potency levels. The respective $I C_{50}$ values obtained ranged between $0.361 \pm 0.15 \mu \mathrm{g} / \mathrm{ml}$ and

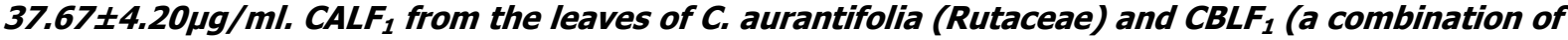
the leaves of $C$. aurantifolia, Carica papaya, Mangifera indica and Psidium guajava) were further screened against a clinical isolate of $P$. falciparum and recorded $I C_{50}$ values similar to those obtained earlier against the laboratory strain, $12.42 \pm 3.94 \mu \mathrm{g} / \mathrm{ml}$ for $C B L F_{1}$ and $29.69 \pm 0.65 \mu \mathrm{g} / \mathrm{ml}$ for CALF $_{1}$ respectively. It could be concluded that majority of the plants have demonstrated appreciable concentration dependent in vitro anti-plasmodial effects against the laboratory adapted and field strains $P$. falciparum.
\end{abstract}

Keywords: Plants Extracts, Traditional Malaria Therapy, Hausa people, Kano, Nigeria

INTRODUCTION

Malaria is a disease caused by protozoan parasites of the genus Plasmodium transmitted by infected female Anopheles mosquitoes. Earlier on, four species, namely $P$. falciparum, $P$. malariae, $P$. ovale, and $P$. vivax were known to cause infection in humans (WHO, 2009). Of recent $P$. knowlesi, a simian species has been implicated to cause infection in humans (Brown, 2011). P. falciparum is the most virulent of the four and is responsible for about $80 \%$ of all malaria cases and about $90 \%$ of the deaths from malaria (WHO, 2010). Malaria is a serious disease with high mortality and morbidity especially in children and pregnant women. Though there had been a slight decline in the malaria incidence over the last few years from 244 million in 2005 to 225 million in 2009. Mortality was projected to have decreased from 985,000 in 2000 to 781000 in 2009. However these large absolute decreases were not observed in Africa (WHO, 2010). The Sub-Saharan Africa bears the highest burden of the disease. A vaccine would have been the ultimate and effective control strategy. However none is available for use. Several vaccines candidate such as RTS, S/AS02A and VAR2CSA are being tested and evaluated. Hence, vector control and chemotherapy remain the major interventions for the control of malaria.

Several drugs particularly chloroquine had been used to treat malaria. However, most of the drugs that we use today are becoming less effective because of the problem of drug resistance (McMorran, 2009). The spate of drug resistance by the malaria parasite particularly $P$. falciparum has necessitated the scientific evaluation of many traditional medicinal plants for an alternative antimalarial drug that is effective, safe and affordable, (Oyedeji et al., 2005). The value of plants in traditional medicine cannot be overemphasized and is still the first point of healthcare for many people in sub-Saharan Africa (WHO, TDR news, 2007; Hostettmann et al., 2000). Plants still provide a source for effective lead compounds against malaria (Midiwo, 2007). The fact that traditional medicinal plants used for the treatment of malaria provided the lead compounds for synthetic antimalarials in use currently gives hope that plants particularly those used in the unorthodox treatment of the disease may provide new lead compounds for development of new and novel antimalarial drugs. It is for this reason that some plants used in the traditional treatment of malaria or fever by the Hausa people of Kano, Nigeria were selected and evaluated for efficacy against the Plasmodium parasite.

\section{MATERIALS AND METHODS}

\section{Collection and Handling of Plant Materials}

Nine plants used in the treatment of malaria or fever (Table 1) were collected on the basis of personal communication with the folks between $21 / 11 / 2008$ to 01/01/2009. 
Taxonomic identification was confirmed by an Ethnobotanist, Professor B. S. Aliyu of the Department of Plant Science, Bayero University Kano, Nigeria. Voucher specimens were deposited in the herbarium of the Bayero University.

Table 1: Plant names, Voucher number, Family and parts collected

\begin{tabular}{lllll}
\hline Plant Name & $\begin{array}{l}\text { Herbarium } \\
\text { Voucher \# }\end{array}$ & Common name & Family & Part used \\
\hline Acacia nilotica & $287 / 05$ & Bagaruwa & Fabaceae & Stem bark \\
Adansonia digitata & $77 / 164$ & Kuka & Bombacaceae & Seeds \& S/bark \\
Carica papaya & $70 / 12$ & Gwanda & Caricaceae & Leaves \\
Cassia occidentalis & $287 / 11$ & Rai-rai & Fabaceae & Leaves \\
Citrus aurantifolia & $20 / 07$ & Lemon-tsami & Rutaceae & Leaves \\
Mangifera indica & $55 / 10$ & Mangwaro & Anacardiaceae & Leaves \\
Moringa oleifera & $30 / 02$ & Zogale & Moringaceae & Leaves \\
Psidium guajava & $66 / 01$ & Goba & Myrtaceae & Leaves \\
Ziziphus mauritiana & $190 / 01$ & Magarya & Rhamnaceae & S/bark \& Leaves \\
\hline
\end{tabular}

Six of the plants, (M. Indica, C. Papaya, P. guajava, C, aurantifolia, C.occidentalis and $M$. oleifera) were prepared as water decoctions. Fresh leaves were collected and washed in clean tap water. They were then drip dried and $50 \mathrm{~g}$ was weighed using Triple Beam Balance 700 SERIES (OHAUS® USA). The leaves were then placed in $500 \mathrm{ml}$ Pyrex $\AA$ beakers and gently boiled for an hour in clean tap water at $1: 5 \mathrm{w} / \mathrm{v}$ (plant part: solvent); i.e. $50 \mathrm{~g} / 250 \mathrm{ml}$. The four plant leaves used as combination ( $M$. Indica, C. Papaya, $P$. guajava, $C$. aurantifolia) were prepared by weighing equal proportions of the respective plants $(12.5 \mathrm{~g}$ each) and stirred to squeeze out the maximum extract from the leaves. The extract was allowed to cool to about $55^{\circ} \mathrm{C}$ before it was filtered using Whatman No. 1 filter paper into a pre-weighed beaker. The filtrate was then concentrated by evaporating the water in shallow containers using Griffin's $₫$ Student Water Bath (WHO, 2002). Individual plant yield was then obtained by differential weighing. Seven aqueous extracts were prepared.

The nine plants parts were shade dried to minimize deterioration of active components. Each dried plant material was then ground into powdered form using mortar and pestle. Two hundred and fifty grams $(250 \mathrm{~g})$ portions was then weighed and extracted as described by Fatope et al. (1993). This carried out by percolating in absolute ethanol (Rjedel-de $\mathrm{Ha} \square \mathrm{n}($ ) ) at $1: 5 \mathrm{w} / \mathrm{v}$ (plant part: solvent); for two weeks and filtered using Whatman $®$ No.1 filter paper. The filtrate was then concentrated by evaporating the solvent using rotary evaporator at $40-45^{\circ} \mathrm{C}$ in a pre-weighed round bottom flask. The yield was then determined by differential weighing. A portion of the extract was transferred into pre-weighed specimen bottle and designated $\mathrm{F} 1$. This was done for all extracts obtained for each of the plants. The remaining bulk of the F1 extract was further successively extracted in $100 \mathrm{ml}$ $(40,30$, and 30$)$ portions of n-Hexane, chloroform, ethyl acetate and finally in methanol for five minutes each. This was allowed to settle for another five minutes before the supernatant was gently decanted into a clean beaker leaving behind the marc. The marc (residue) was allowed to dry before extracting with the next solvent. The decanted portions for each solvent were pooled together and the solvent removed by rotary evaporation and designated $F_{2}$, for $n$ hexane; $F_{3}$, for chloroform; $F_{4}$, for ethyl acetate and $F_{5}$, for methanol fractions respectively. A total of 55 extracts and fractions were thus obtained in this process. A total of sixty three extracts (7 aqueous and 55 organic) were obtained using the two procedures.

\section{In vitro Antiplasmodial Activities of Extracts}

Laboratory strains of chloroquine susceptible strain of $P$. falciparum, 3D7 and a clinical isolate maintained in washed human blood group $\mathrm{O}+$ type suspended in complete parasite medium , CPM (RPMI 1640 medium supplemented with gentamicin + I-glutamine + albumax) in long term continuous in vitro cultivation in the Immunology Department of the Noguchi Memorial Institute of Medical Research (NMIMR), University of Ghana, Legon (Trager and Jensen, 1976), with slight modifications (Ofori et al., 2002) were used for the assay. Thirty extracts [7 aqueous extracts, 12 ethanol $\left(F_{1}\right)$ and 11 methanol $\left(F_{5}\right)$ extracts] were selected for the preliminary assay $\mathrm{W}$ against stabilised parasite cultures containing largely ring stages. The extracts were dissolved in microquantities of water, ethanol or methanol depending on the solvent of extraction. The resulting solutions were then diluted with RPMI 1640 such that the final ethanol and methanol concentrations did exceed $0.01 \%$. For the preliminary assay each extracts was tested at three duplicate concentrations of 5,50 and $100 \mu \mathrm{g} / \mathrm{ml}$ using 24-well microtitre plates. Nine hundred microlitres of $1 \%$ parasite culture was placed in each well. One hundred microlitres of the solution of the test extract in RPMI 1640 containing the requisite concentration were added to give a final volume of $1000 \mu \mathrm{l}$ in each well. Based on the criterion of Prozesky et al., (2001) (the most active extract giving more than $70 \%$ inhibition at $50 \mu \mathrm{g} / \mathrm{ml}$ in the preliminary assay) was used as basis of selecting extracts for re-evaluation.

Seven extracts were selected for further evaluation, using two-fold serial dilutions ranging from $0.78125 \mu \mathrm{g} / \mathrm{ml}$ to $200 \mu \mathrm{g} / \mathrm{ml}$ 24-well microtitre plates in duplicate for each extract. Artesunate was also tested alongside these extracts as standard control. CALF $_{1}$ and $\mathrm{CBLF}_{1}$ extracts were also evaluated against field strain $P$. falciparum. 
The assay plates were placed in Billups-Rothenberg Modular Incubating Chamber (patent no. 5352414, USA) and flushed with a gentle flow of a mixture of $2 \% \mathrm{O}_{2}, 5.5 \% \mathrm{CO}_{2}$ and $92.5 \% \mathrm{~N}_{2}$ gases and finally incubated in Galaxy $170 \mathrm{~S}$ brand incubator (RS Biotech UK) set $a t 37^{\circ} \mathrm{C}$ for $48 \mathrm{~h}$.

Parasitaemia Estimation and IC $_{\mathbf{5 0}}$
Determination
Parasitaemia was estimated by microscopic
observation of completely dried thin slide films
prepared from each assay well under the x100
objective in oil immersion using the Olympus binocular
microscope, (Model CH30 Japan) (WHO 1991;
NMIMR/SOP). A minimum of 500 RBCs were counted
against the parasitized/infected cells in the preliminary
assay, while 1000 cells were counted in the extended

\section{RESULTS}

Aqueous extraction of the plants gave extract yields ranging from $4.5 \mathrm{~g}$ (9\%) for $C$. papaya to $8.04 \mathrm{~g}$ assay. Estimate of \% parasitaemia was determined by the relation: \%parasitaemia $=[$ (no. of infected cells $\div$ total cell count) $\times 100 \%]$

Once the $\%$ parasitaemia was determined for a particular extract concentration, this was transformed into percentage inhibition of growth by comparison with control values (Addae-Kyereme, et. al., 2001). This is given by the relation: $[(a-b) / a] \times 100 \%$; Where $a=\%$ parasitaemia in control and $b=\%$ parasitaemia in treatment.

The half maximal inhibitory concentration, $\mathrm{IC}_{50}$ for an extract was determined by plotting the \% inhibition against the logarithms of the concentrations in Microsoft Office Excel Worksheet. Regression equation was used to compute the $\mathrm{IC}_{50}$ values based on the equation of the slope given as: $[y=a x+c]$.

(16.09\%) for C. occidentalis (Table 2). The extracts were generally green in colour and pasty or gummy in texture.

Table 2: Yields from Aqueous Extraction

\begin{tabular}{|c|c|c|c|c|c|c|}
\hline PLANT NAME & FAMILY & PART & CODE & $\begin{array}{c}\text { FRESHWT. } \\
(\mathrm{g})\end{array}$ & $\begin{array}{l}\text { EXTRACT } \\
\text { WT. (g) }\end{array}$ & \%YIELD \\
\hline C. aurantifolia & Rutaceae & Leaves & CALW & 50 & 5.05 & 10.10. \\
\hline C. occidentalis & Fabaceae & Leaves & COLW & 50 & 8.04 & 16.09 \\
\hline C. papaya & Caricaceae & Leaves & CPLW & 50 & 4.50 & 9.00 \\
\hline M. indica & Anacardiaceae & Leaves & MILW & 50 & 7.30 & 14.60 \\
\hline M. oleifera & Moringaceae & Leaves & MOLW & 50 & 7.80 & 15.60 \\
\hline P. guajava & Myrtaceae & Leaves & PGLW & 50 & 6.50 & 13.00 \\
\hline Combination* & -------- & Leaves & CBLW & 50 & 6.50 & 13.00 \\
\hline
\end{tabular}

*A combination of M. indica, C. papaya, P. guajava \& C. aurantifolia in equal proportions;

The yields for the $\mathrm{F}_{1}$ extracts ranged from $6.9 \mathrm{~g}(4.6 \%)$ for the stem back of $A$. digitata to $58.3 \mathrm{~g}(23.32 \%)$ for the leaves of $P$. guajava. The leafy parts mostly yielded products which were green or grey in colour, and gummy or oily in texture. Extract of the leaves of $P$. guajava $\left(\mathrm{PGLF}_{3}\right)$ was crystalline. The stem-bark materials mostly yielded materials which were brown, yellow or red with their texture varied from pasty to powdery substances.

At $5 \mu \mathrm{g} / \mathrm{ml}$ concentration, ADSF $_{1}$ (with $54 \%$ inhibition) and $\mathrm{ZMLF}_{1}$ (with $54.82 \%$ inhibition) exhibited the best inhibition. No extract had up to $70 \%$ inhibition at $5 \mu \mathrm{g} / \mathrm{ml}$ concentration (Table 4 ). Seven (or 23.33\%) exhibited up to 70 or more \% inhibition at $50 \mu \mathrm{g} / \mathrm{ml}$ concentration. These extracts were $\mathrm{CBLF}_{5}(88.49 \%)$, $\mathrm{MILF}_{1}(82.51 \%), \mathrm{MILF}_{5}(80.41 \%), \mathrm{ANSF}_{1}(78.33 \%)$, $\mathrm{CALF}_{1}(75.97 \%), \mathrm{ANSF}_{5}(74.45 \%)$ and $\mathrm{CBLF}_{1}$ $(70.07 \%)$. However, at $100 \mu \mathrm{g} / \mathrm{ml}$ concentration, 15 or (50\%) of the extracts had $70 \%$ or more inhibition.

The extracts evaluated in the detailed analysis, exhibited concentration dependant inhibition activities on the parasite as indicated by the mean percentage inhibitions in the two experiments. A graphical presentation of this interactions developed using the Sigma Plot Program (Version 9) is presented in Figure 1. 


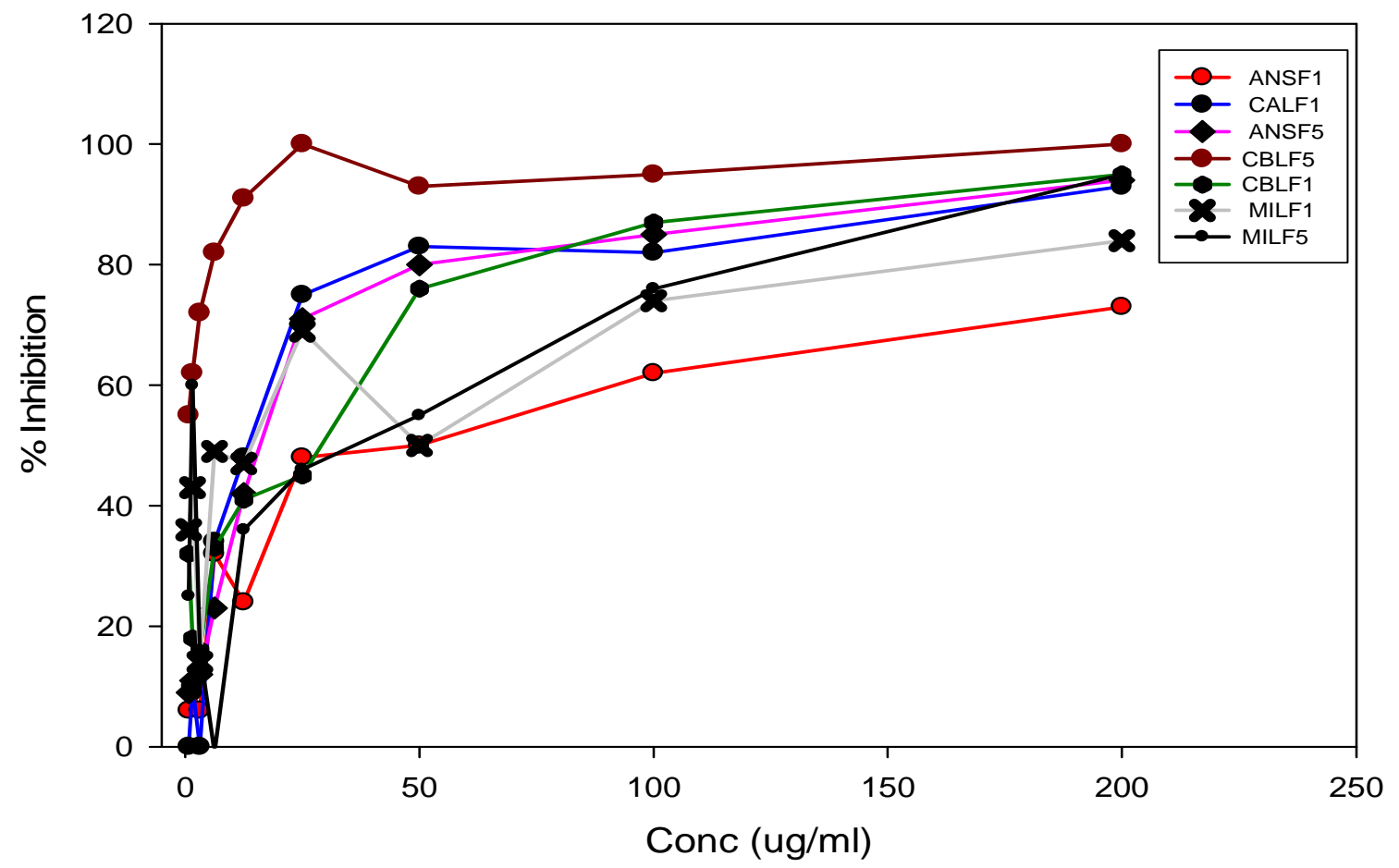

Figure 1: Inhibition Characteristics of Seven Selected Extracts in the Detailed Evaluation Assay against 3D7 Pf

$\mathrm{CBLF}_{5}$ [prepared from four combined plants namely $M$. indica, (Anacardiaceae); C. papaya, (Caricaceae); $P$. guajava, (Myrtaceae); and C. aurantifolia, (Rutaceae)] exhibited the highest \% inhibition (55\% Inhibition) at the lowest concentration $(0.78125 \mu \mathrm{g} / \mathrm{mL})$ and $\mathrm{IC}_{50}$ of $0.361 \mu \mathrm{g} / \mathrm{mL}$. ANSF ${ }_{1}$ on the other hand had the least effect $\left(\mathrm{IC}_{50}\right.$ of $\left.37.67 \mu \mathrm{g} / \mathrm{ml}\right)$. However, as the concentrations of the extracts increases, the percent inhibition also increased. In addition the ethanol

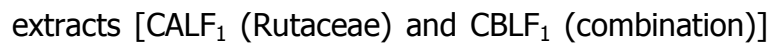
selected and evaluated against the field strain of $P$. falciparum also exhibited concentration dependant inhibition characteristics with $\mathrm{IC}_{50} \mathrm{~S}$ of $12.42 \pm 3.94$ $\mu \mathrm{g} / \mathrm{ml}$ for $\mathrm{CBLF}_{1}$ and $29.69 \pm 0.65 \mu \mathrm{g} / \mathrm{ml}$ for $\mathrm{CALF}_{1}$ against the field strain.

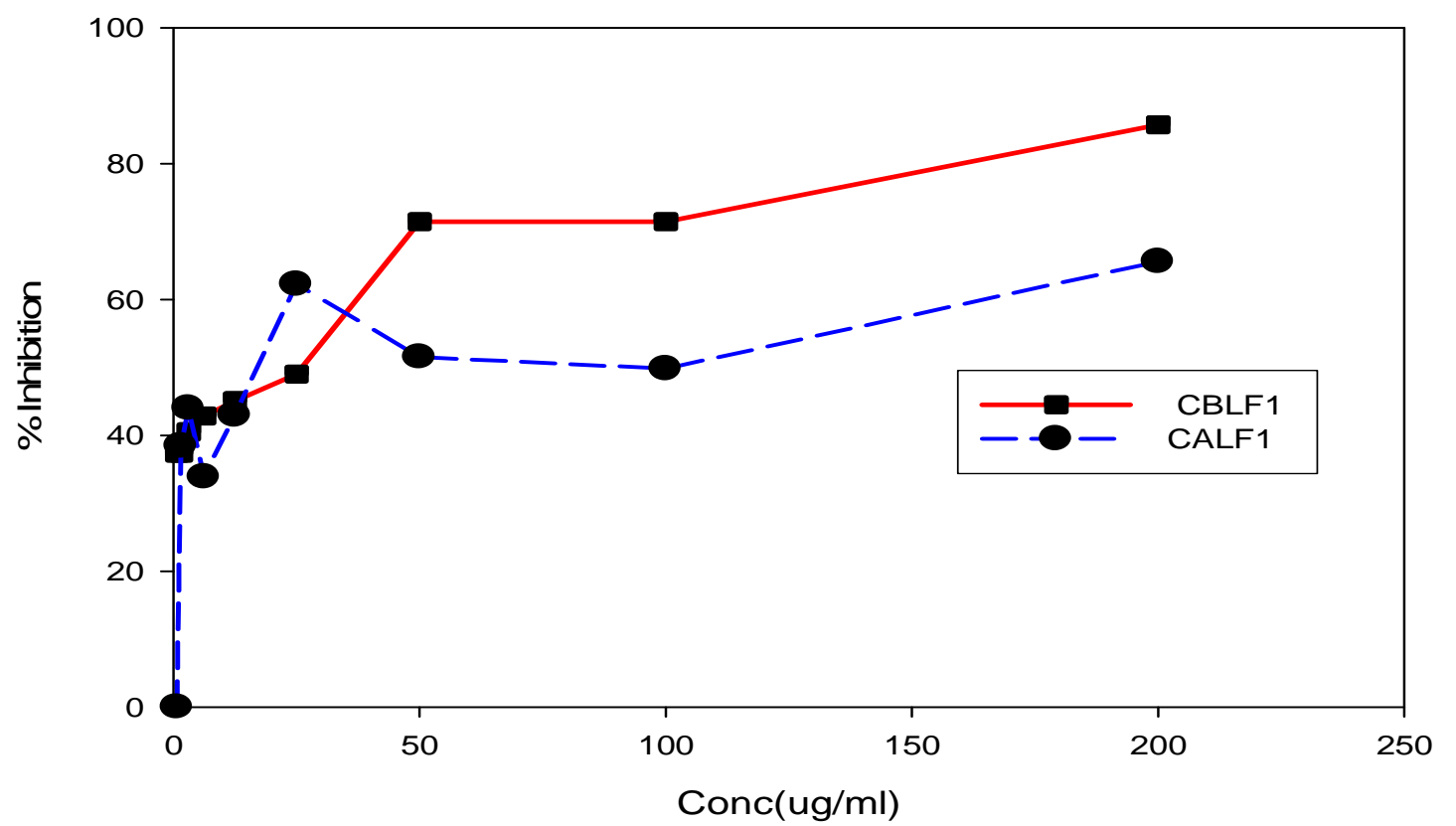

Figure 2: Inhibition Characteristics of Two Selected Extracts in the Detailed Evaluation Assay against a field isolate $P f$ 
Artesunate (a standard drug) evaluated against 3D7 $P$. falciparum also exhibited concentration dependant inhibition characteristic with extremely low $\mathrm{IC}_{50}$ of $0.00012 \pm 0.000041 \mu \mathrm{g} / \mathrm{ml}$. This result was not to compare with the plant extracts.

\section{DISCUSSION}

Hot aqueous extractions (decoctions) were employed in this work in a bid to evaluate the rationale of the traditional method of boiling fresh herbs / leaves in clean potable water. In addition, a combination of four of the plants ( $M$. Indica, C. Papaya, P. guajava, and $C$, aurantifolia) also was to depict the typical traditional concoction mode of preparation of these plants. The yields obtained for both protocols shows how maximally the phyto-contents of the drug plants can be exploited in the traditional method thereby exposing the parasite to reasonably high dosages of the active phytochemicals in the patient. The moderate in vitro activities exhibited by the aqueous extracts despite the hot mode of extraction, in the preliminary assay confirms the stability of the active principles in these plants which gives credence to the traditional mode of preparation in malaria therapy. The activity exhibited by some of the aqueous extracts confirms the scientific rationale of the use of the plants in traditional malaria therapy. The lower efficacy exhibited by aqueous extracts in the assay compared to the organic solvents extracts was not unusual as earlier observed by Kirira et al., (2006), and Mostafa et al., (2007). Also in an in vivo study, the aqueous extract of $C$. occidentalis was reported to be less active than the corresponding ethanolic extract (Tona et al. 2001). The organic extracts $F_{1}$ and $F_{5}$ demonstrated relatively higher activities in the preliminary in vitro assay compared to the aqueous extracts. This was consistent with the report of Mbatchi et al., (2006). Perhaps this sharp difference in bioactivity over the aqueous extracts points to the minimal destruction of other active compounds and/or a refining effect of synergistic properties of compounds in the organic fractions.

The activity of the $F_{1}$ extract of $Z_{M L F}$ (Rhamnaceae) on the 3D7 strain of $P f$ corroborates the report by Panseeta et al. (2011). The activity exhibited by $\mathrm{ADSF}_{1}$ (Bombacaceae) is in consonance with the report of Kohler et al., (2002), who reported the activity of the lipophilic extract of $A$. digitata (Bombacaceae) on the laboratory adapted $P$. falciparum species PoW and Dd2 with $\mathrm{IC}_{50}>50 \mu \mathrm{g} / \mathrm{ml}$. The activity demonstrated by the concoctions' extracts only confirms the scientific worth of this traditional therapy. It also suggests that the constituent plants possibly inhibit the $P$. falciparum malaria parasite in a synergistic mode. Fiot et al., (2006) had reported a similar phenomenon with $G$. senegalensis, Mitragyna

\section{REFERENCES}

Addae-Kyereme J., Croft, S.L., Kendrick, H. \& Wright, C.W.,(2001) Antiplasmodia activities of some Ghanaian plants traditionally used for fever/malaria treatment \& of some alkaloids isolated from Pleiocarpa mutica; in vivo inermis and Pavetta crassipes plants commonly used in combination to treat malaria.

The preliminary in vitro assay provided baseline data on the antiplasmodial properties of the plants and warrants a closer evaluation to generate a more reliable data for further considerations; hence the subsequent phases of the assays on selected plants extracts. Result obtained strongly indicated that the plants possess significant antiplasmodial action against the 3D7 Pf. in vitro. Six out of these extracts yielded $\mathrm{IC}_{50} \mathrm{~S}$ below $20 \mu \mathrm{g} / \mathrm{ml}$. The activity demonstrated by $\mathrm{CBLF}_{1} \quad(15.07 \pm 1.74 \mu \mathrm{g} / \mathrm{ml})$ and $\mathrm{CBLF}_{5}$ $(0.361 \pm 0.15 \mu \mathrm{g} / \mathrm{ml})$ only further affirms the value of combination of plants (C. papaya, $C$. aurantifolia, $P$. guajava and $M$. indica) normally used in traditional malaria treatment by the Hausas of Kano.

The $\mathrm{IC}_{50}$ for $\mathrm{ANSF}_{1}$ (Fabaceae), $37.67 \pm 4.20 \mu \mathrm{g} / \mathrm{ml}$ and ANSF $_{5}, 12.51 \pm 1.89 \mu \mathrm{g} / \mathrm{ml}$ in this work is by far lower than what was earlier reported for $A$. nilotica $(73.59 \pm 2.87 \mu \mathrm{g} / \mathrm{ml}$ and $70.33 \pm 1.89 \mu \mathrm{g} / \mathrm{ml})$ on laboratory $P$. falciparum cultures of ENT30CQ resistant isolate and NF54CQ sensitive strain respectively by Kirira et al., (2006). However, El-Tahir et al. (1999) earlier reported that the ethyl acetate extract of $A$. nilotica produced an $\mathrm{IC}_{50}<5 \mu \mathrm{g} / \mathrm{ml}$. The efficacy observed against clinical strains of $P$. falciparum $\left(\mathrm{IC}_{50} \mathrm{~S}\right.$ for $\mathrm{CBLF}_{1} \quad\left(12.42 \pm 3.94 \mu \mathrm{g} / \mathrm{ml}\right.$ and $\mathrm{CALF}_{1}$ $(29.69 \pm 0.65 \mu \mathrm{g} / \mathrm{ml})$ indicated that these extract indeed hold promise as antimalarial agents. The activity observed for $\mathrm{CALF}_{1}$ (Rutaceae) further corroborates earlier report that a number of members of the Rutaceae have indeed antimalarial activity (Schwikkard van and Heerden, 2002; Rukunga et al. 2009). Artesunate exhibited a concentration dependant characteristic against the laboratory strain Pf and $\mathrm{IC}_{50}$ of $0.00012 \mu \mathrm{g} / \mathrm{ml}$. This observation further confirmed the effectiveness of this drug on the parasite.

\section{CONCLUSION}

It can be concluded that some of the plants evaluated in this study indeed posses' antiplasmodial effects. Also the extracts prepared from the combination of four plants ( $C$. papaya, $C$. aurantifolia, $P$. guajava and $M$. indica) $\mathrm{CBLF}_{1}$ and $\mathrm{CBLF}_{5}$ demonstrated the best antiplasmodial activities with $\mathrm{IC}_{50}$ values of $15.07 \pm 1.74 \mu \mathrm{g} / \mathrm{ml}$ and $0.361 \pm 0.15 \mu \mathrm{g} / \mathrm{ml}$ respectively. Thus, suggesting that the plants have synergistic effects.

\section{Acknowledgements}

The support of the Bayero University, Kano, Nigeria and the Management and staff of the Noguchi Memorial Institute of Medical Research NMIMR, University of Ghana Legon is here by appreciated and acknowledged.

antimalarial activity of pleiocarpine. $J$. Ethnopharmacol. 76(1):p $99-103$.

El Tahir, A., Satti, G. M., \& Khalid, S. A. (1999 $)$ Antiplasmodial activity of selected Sudanese medicinal plants with emphasis on Maytenus senegalensis (Lam.) Exell. J. Ethnopharmacol. 64 (3): p227 - 233. 
El-Tahir A., Satti G. M., \& Khalid, S. A. (1999 $\left.{ }^{b}\right)$ Antiplasmodial activity of selected Sudanese medicinal plants with emphasis on Acacia nilotica. Phytother Res. 13 (6): p474-478.

Fatope, M. O., Ibrahim, H. \& Takeda, Y. (1993) Screening of Higher Plants Reputed as Pesticides using the Brine Shrimp Lethality Assay. Int. J. Pharmacog., 31 (4): p250 254.

Fiot, J., Sanon, S., Azas, N., Mahiou, V., Jansen, O., Angenot, L., Balansard, G. \& Ollivier, E. (2006) Phytochemical \& pharmacological study of roots \& leaves of Guiera senegalensis J.F. Gmel (Combretaceae). J Ethnopharmacol.

Hostettmann, K., Marston, A., Ndjoko, K. \& Wolfender, J. L. (2000) The Potential of African Plants as a source of Drugs. Curr. Org. Chem. (4): p973 - 1010 .

Kirira, P. G., Rukunga, G. M., Wanyonyi, A. W., Muregi, F. M., Gathirwa, J. W., Muthaura, C. N., Omar, S. A., Tolob, F., Mungaid, G. M. \&. Ndiege, I. O., (2006) Anti-plasmodial activity \& toxicity of extracts of plants used in traditional malaria therapy in Meru \& Kilifi Districts of Kenya. J. Ethnopharmacol 106: p403-407

Kohler, I., Jenett-Siems, K., Siems, K., Hern\&ez, M. A., Ibarra, R. A., Berendsohn, W. G., Lamb, T. J. \& Langhorne, J. (2002). The severity of malarial anaemia in Plasmodium chabaudi infections of BALB/C mice is determined independently of the number of circulating parasites. Malaria Journal, 7(1): p68

Mbatchi, S. F., Mbatchi, B., Banzouzi, J. T., Bansimba, T. N., Nt\&ou, G. F., Ouamba, J. M., Berry, A. \& Benoit-Vical, F. (2006) In vitro antiplasmodial activity of 18 plants used in Congo Brazzaville traditional medicine. $J$. Ethnopharmacol. 104(1-2):p168-174.

McMorran , B. (2009) New hope for better malaria treatment. ABC Privacy Policy @: http://www.abc.net.au

Midiwo, J. (2007) The Hunt for the Next Artemisinin. WHO-TDRnews Number 79:p9 - 12 .

Mustofa, E. N. S. \& Subagus, W. (2007) In vitro \& in vivo Antiplasmodial Activity \& Cytotoxicity of Extracts of Phyllanthus Niruri L. Herbs Traditionally Used To Treat Malaria In Indonesia. Southeast Asian J Trop Med Public Health 38 (4): p609 - 615.

Ofori, M. F., Dodoo, D., Staalsoe, T., Kurtzhals, J. A., Koram, K., Theander, T. G., Akanmori, B. D. \& Hviid, L. (2002) Malaria-induced acquisition of antibodies to Plasmodium falciparum variant surface antigens. Infect Immun. 70(6): p2982-2988.

Oyedeji, S. I., Bassi, P. U., Awodebode, H. O. \& Olumese, P. E. (2005). Comparative assessment of Plasmodium falciparum sensitivity to chloroquine \& amodiaquine in vitro. Afr J. of Biotechnol., 4(11):p1317 1320.

Panseeta, P., Lomchoey, K., Prabpai, S., Kongsaeree, P., Suksamrarn, A., Ruchirawat, \& Suksamrarn, S. S. (2011) Antiplasmodial and antimycobacterial cyclopeptide alkaloids from the root of Ziziphus mauritiana Phytochemistry 72: p909-915

Prozesky, E. A., Meyer, J. J., \& Louw, A. I. (2001). In vitro antiplasmodial activity \& cytotoxicity of ethnobotanically selected South African plants. J. Ethnopharmacol. 76 (3):239 - 245.

Rukunga, G. M., Gathirwa, J. W., Omar, S. A., Muregi, F. W. Muthaura, C. N. Kirira, P. G., Mungai, G. M. and Kofi-Tsekpo, W. M. (2009). Antiplasmodial activity of the extracts of some Kenyan medicinal plants J. Ethnopharmacol, 121(2) p282 - 285.

Schwikkard, S.and van Heerden, F. R. (2002). Antimalarial activity of plant metabolites. Nat Prod Rep. 19 (6):p675-92

Tona, L., Mesia, K., Ngimbi, N. P., Chrimwami, B., Okond'ahoka, C. K., de Bruyne, T., Apers, S., Hermans, N., Totte, J., Pieters, L., \& Vlietinck, A. J. (2001) In-vivo antimalarial activity of Cassia occidentalis, Morinda morindoides \& Phyllanthus niruri Ann Trop Med Parasitol. 95 (1):p47 - 57.

Trager, W. \& Jensen, J. B. (1976) Human malaria parasites in Continuous culture. Science 193: $\mathrm{p} 673-675$.

World Health Organisation, WHO (1991) Basic Malaria Microscopy (part I \& II) Reprinted 1995, 1998Geneva. Pp1- 48.

World Health Organization WHO, (2002) Quality Control Methods for medicinal plant Materials. A. I. T. B. S. Publishers \& Distributers (Regd.) IndiaP: 30.

World Health Organization, WHO (2009) Malaria fact sheet N94 Updated January 2009

World Health Organization, WHO (2010) WHO Global Malaria Programme, World Malaria Report 2010: p1-62.

WHO/TDR news (2007) 'TDR's Molecular Entomology Committee Helped unlocks Mosquito genome's secrets'. TDR news No 79: p28 30. 